\title{
3\% uplift: Long-term approach needed to make NHS dentistry a going concern
}

The British Dental Association has said a long-term approach to pay is now required to keep NHS dentistry viable, following confirmation of a 3\% pay award.

The pay award meets the recommendations made in the 49th report of the Review Body on Doctors' and Dentists' Remuneration (DDRB) in full, and marks the third consecutive above-inflation increase following a decade of pay restraint, which saw real incomes for practitioners fall by over $35 \%$.

The pandemic has added to long-term pressures facing general dental services

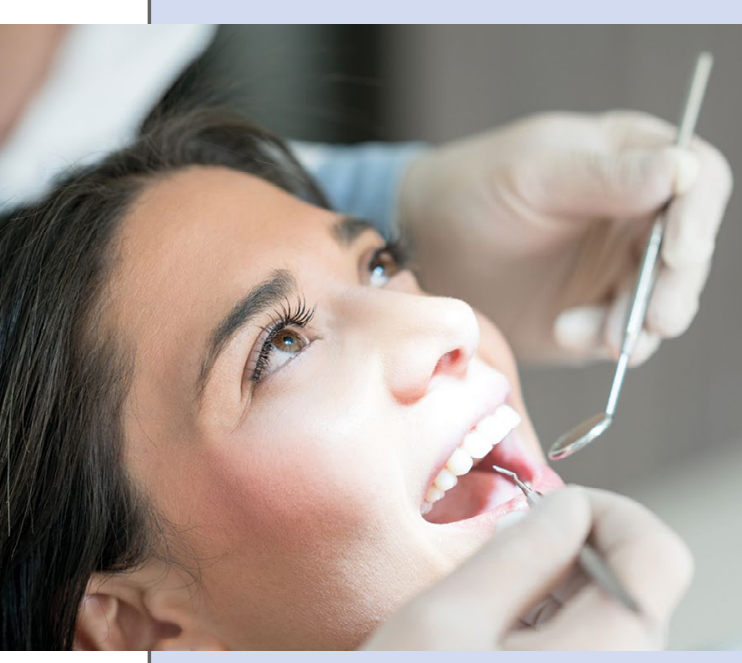

across the UK. Recent surveys indicate nearly half (47\%) of dentists in England are now likely to reduce their NHS commitment, should current restrictions remain in place, with the same proportion indicating they will seek early retirement or a change in career.

With inflation now at $2.5 \%$ the BDA has stressed an ongoing commitment to fair pay is required to guarantee the long-term sustainability of the service, alongside parallel action on a roadmap to ease pandemic restrictions, and meaningful reform of the contractual systems NHS dentistry operates to. The discredited activitybased systems in operation across the UK have fuelled recruitment and retention problems and have proved unworkable since lockdown.

The announcement will see the $3 \%$ uplift on pay backdated to
April, with no staging. This will apply to community dentists in full, with a final uplift to contract values for general dental practitioners to be confirmed following consultations on expenses in the four UK nations. Consultants will see a $3 \%$ uplift in basic pay (Specialty and Associate Specialists (SAS) and Juniors have separately agreed pay deals). The BDA has encouraged practice owners to engage with their associate dentists to discuss their contractual arrangements in light of the uplift.

BDA Deputy Chair Peter Crooks said: 'An uplift on the right side of inflation is progress. A decade of pay restraint has taken its toll, and we can never return to recommendations that fail to reflect the cost of living.

'Both providers and performers need to see the benefit of this uplift. This has been a hard year for practices, but we look to owners to ensure this increase reaches their associates.

'Even before COVID-19, a growing number of colleagues saw no future in the NHS. If we're ever going to make this service a going concern then fair pay must remain the rule.'

\section{Remote orthodontics: BDA back CQC moves on registration}

The British Dental Association has applauded moves by the Care Quality Commission requiring remote orthodontic providers to be registered with them in order to practise lawfully.

The watchdog has stated that remote orthodontics comes under the regulated activities of 'Treatment of disease, disorder or injury' and 'Diagnostic and screening procedures' and as such requires registration, and by extension inspection.

The Commission notes that 'to register with us, providers must assure us that they are able to provide safe and effective care in line with relevant legislation and guidance' and has indicated its willingness to prosecute providers who fail to register.

The General Dental Council recently acknowledged vital principles long advocated by the BDA that orthodontic patients need to be fully assessed by a dentist, that direct dentist-to-patient interaction - the basis for informed consent - is essential, and that patients must know the name and registration number of the dentist responsible for their care. However, while offering warnings to patients the regulator failed to set out any sanctions to providers who departed from these principles.

Remote provision is growing in popularity, but can lead to irreversible damage to a patient's mouth.

BDA Chair Eddie Crouch said: 'With remote orthodontics we need real regulation, not just empty warnings to properly protect patients.

'Mandatory CQC registration and inspection is a much-needed first step. A health watchdog needs teeth, and a willingness to prosecute those who fail to register is sending the right signal to unscrupulous operators.' In a recent BOS members' survey (April 2021), 82\% of members were 'concerned about more patients seeking DIY orthodontics during and following the pandemic'. In fact, it has been a concern for BOS members for a number of years.

British Orthodontic Society Director of External Relations, Anjli Patel commented: 'This news from the CQC is very welcome. This is something that BOS have been calling for, for a long time. As we have highlighted before, this is a patient safety issue and we hope that this action will provide more certainty for those seeking orthodontic treatment.

One of our primary concerns about DIY orthodontics is that many patients were said to be unaware of the identity of their supervising dentists. Today's announcement will mean this is rectified.' 